\title{
Caracterização química e aspectos geoquímicos relevantes da matéria orgânica de sedimentos em suspensão na foz do rio Amazonas ${ }^{1}$ \\ Chemical characterization and relevant geochemical aspects of suspended organic matter on the Amazon river delta
}

Resumo: As características geoambientais do rio Amazonas têm sido descritas por diversos pesquisadores, enfatizando a apreciável extensão de sua bacia de drenagem, a influência da floresta, da erosão, da sazonalidade, do considerável índice pluviométrico, do transporte de material em suspensão e da notável descarga (vazão) lançada para o oceano Atlântico. Este estudo, realizado no âmbito do Programa Recursos Vivos da Zona Econômica Exclusiva (REVIZEE), em amostras de sedimentos coletadas em águas costeiras do oceano Atlântico sob influência do rio Amazonas, durante $\circ 2^{\circ}$ cruzeiro científico da Operação Norte II, a bordo do navio oceanográfico Anatares, procede à caracterização química e discute aspectos geoquímicos relevantes da matéria orgânica de sedimentos de fundo e em suspensão na foz do grande rio. Observou-se que as concentrações mais elevadas de material em suspensão (máxima em 2300 mg/L) encontram-se em pontos de coleta próximos à costa e tendem a zero a offshore. A variação do teor da matéria orgânica associada a esse material em suspensão é relativamente restrita (mínimo em 1,91\% e máximo em 3,53\%). A identificação da natureza química da matéria orgânica indica a ocorrência de material húmico, associado muito provavelmente à drenagem de solos amazônicos característicos, como os podzóis e os latossolos, material esse transportado pelo rio Amazonas até as águas costeiras. Na caracterização química do material húmico, identificaram-se grupos metileno (que estão diretamente relacionados com hidrocarbonetos alifáticos), grupos $\mathrm{C}=\mathrm{O}$ (de carboxilato e de cetonas) e de bandas devidas a argilominerais associados. O teor de matéria orgânica mostrouse sempre abaixo de 3,6\%, exibindo valores de razão C/N variando de 9,64 (material em suspensão) a 68,3 (em sedimentos de fundo), de acordo com a maior ou menor influência de compostos orgânicos nitrogenados ou de maior ou menor período de maturação desse material orgânico. Nas amostras apresentando razão C/N mais elevadas, deve-se esperar uma origem em que dominem produtos da decomposição de celulose ou que estejam associadas a um período de maturação menos recente. $O$ teor de fosfato presente no sedimento, variando de 0,06\% a 0,78\% (expressos em mg. $L^{-1}$ de P), sugere influências do ambiente marinho (talvez envolvendo contribuições de $\mathrm{P}$ biogênico), através da ressuspensão de sedimentos, fato comum em ambientes estuarinos.

Palavras-chave: Geoquímica. Sedimentos. Matéria orgânica. Material húmico. Foz do rio Amazonas.

\footnotetext{
I Prefeitura Municipal de Vitória. Espírito Santo, Brasil (sbaia3000@yahoo.com.br).

II Universidade Federal do Pará. Centro de Geociências. Belém, Pará, Brasil (waterloo@ufpa.br) (robrini@ufpa.br).

1 Parte da dissertação de mestrado da primeira autora, do curso de pós-graduação da Universidade Federal do Pará.
}

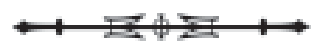


Abstract: Characteristics of geoenvironment of the Amazon river have been described by several researchers, where the appreciable extension of its drainage basin, the influence of the forest, erosion, seasonality, the considerable pluviometric index, the material transported in suspension and the notable discharge flown by the Atlantic ocean have been emphasized. This study, accomplished in Alive Resources of the exclusive Economic Zone Program (REVIZEE) ambit, in sediments samples collected in coastal waters of the Atlantic ocean under influence of the Amazon river, during the $2^{\text {nd }}$ scientific cruise of the North Operation II, on ship-board Antares oceanographic, proceeds chemical characterization and it discusses important geochemistry aspects of the organic matter from bottom sediments and in suspension in the mouth of the great river. It was observed that the high concentrations of the suspended matter (maxim in $2300 \mathrm{mg} \cdot \mathrm{L}^{-1}$ ) are met in collection points close to the coast, tending to zero off shore. The variation of the content of the organic matter associated to that suspended matter is relatively restricted (minimal in 1,91\% and maximum in 3,53\%). The identification of the chemical nature of the organic matter indicates the occurrence of humic material, probably associated to the drainage of characteristic amazon soils, as the podzols and the latosols, material transported by Amazon River as far as coastal waters. The chemical characterization of the humic material identified groups methylene (directly related with aliphatic hydrocarbons), of groups $\mathrm{C}=\mathrm{O}$ (of carboxylate and/or ketones) and of bands owed the associated clayminerals. The content of organic matter was always shown below $3,6 \%$, exhibiting reason values $\mathrm{C} / \mathrm{N}$ varying from 9,64 (suspended matter) to 68,3 (bottom sediments), in agreement with the largest or smaller influence of nitrogen organic compounds and/or largest or smaller period of maturation of the organic material. In samples presenting higher reasons $\mathrm{C} / \mathrm{N}$; an origin should be waited in that dominate products of the decomposition of cellulose and/or which are associated to a period of more recent maturation. The content of present phosphate in the sediment, varying from $0,06 \%$ to $0,78 \%$ (expressed in $m g . L^{-1}$ of $P$ ), suggests marine influences of the ambient (perhaps involving contributions of $\mathrm{P}$ biogenic), through the resuspension of sediments, being common in estuarines environments.

Keywords: Geochemistry. Sediments. Organic matter. Humic material. Mouth of the Amazon river.

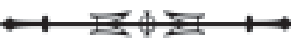




\section{INTRODUÇÃO}

As características geoambientais do rio Amazonas têm sido descritas na literatura, que enfatiza a apreciável extensão de sua bacia de drenagem; a influência da floresta, da erosão, da sazonalidade, do considerável índice pluviométrico; do transporte de material em suspensão e da notável descarga lançada para o oceano Atlântico (DEGENS; KEMPE; RICHEY, 1991).

A decomposição da matéria orgânica associada aos sedimentos provoca modificações que influenciam no ciclo biogeoquímico de vários elementos, determinando a forma na qual os mesmos encontram-se ali presentes. Essas modificações consistem de reações diagenéticas capazes de produzir decomposição de matéria orgânica reduzida, material húmico e quelação de metais (BERNER; BERNER, 1996).

Esta investigação visa à avaliação do conteúdo e da natureza da matéria orgânica associada aos sedimentos em suspensão e, em alguns casos, amostras de sedimentos de fundo na foz do rio Amazonas, a partir da análise química elementar para carbono, nitrogênio, hidrogênio, termogramas e de espectros de registros de absorção na região do infravermelho.

\section{MATERIAL E MÉTODOS}

\section{Amostragem}

Executaram-se os trabalhos de campo no âmbito da Operação Norte II do Programa Recursos Vivos da Zona Econômica Exclusiva (REVIZEE), no período de 13 a 23 de outubro de 1997, a bordo do navio oceanográfico Antares. A amostragem foi realizada no período de estiagem. Os pontos de amostragem foram georeferenciados por meio do sistema de posicionamento global, o GPS (Global Positionning System).

O material geológico (13 amostras) foi coletado em águas costeiras do oceano Atlântico sob influência do rio Amazonas. As amostras foram coletadas em amostrador do tipo Rosette e separadas através de filtro Millipore com abertura de 0,45 $\mathrm{mm}$. Do total de 36 pontos amostrados pelo Programa Revizee, 11 apresentaram, após filtração, material suficiente para as análises (Figura 1) e, destes pontos,

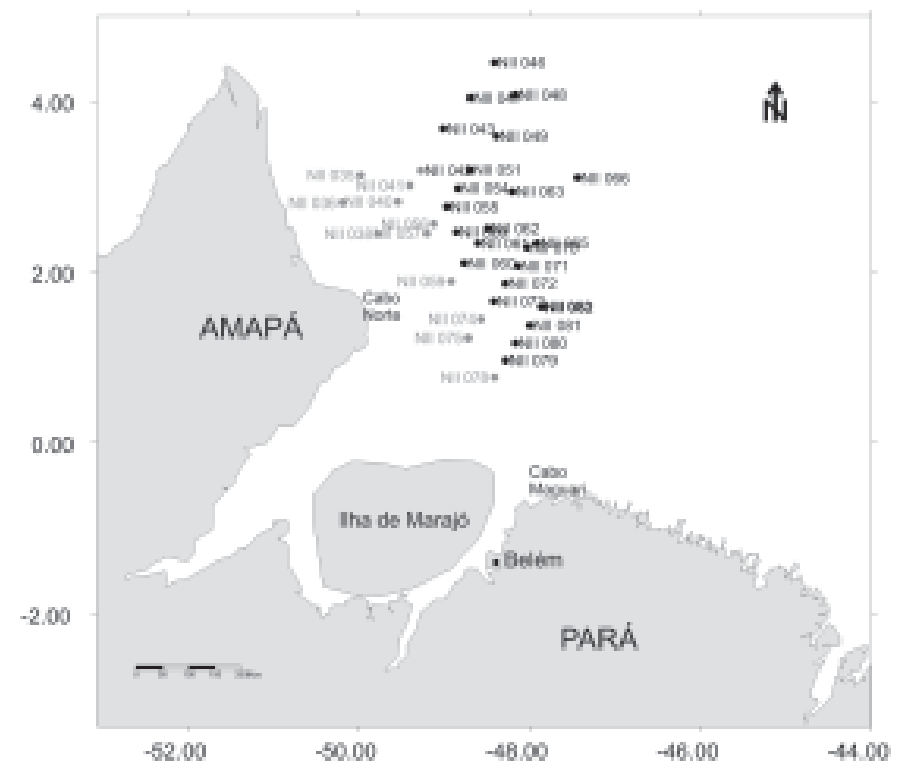

Figura 1. Mapa dos pontos de amostragem na foz do rio Amazonas.

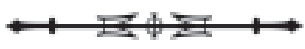

169 
selecionaram-se as amostras para este estudo (Tabela 1). Realizou-se a coleta de material particulado em vários níveis de profundidade através de um amostrador do tipo Rosette (composto por 12 garrafas de Niskin) acoplado a um CTD (medidor de condutividade, temperatura e densidade).

Tabela 1. Apresentação dos pontos de amostragem (36-5 referese à amostra coletada na estação 36 a aproximadamente $5 \mathrm{~m}$, 36-F refere-se à amostra 36 coletada no fundo e assim sucessivamente).

\begin{tabular}{ccc}
\hline $\begin{array}{c}\text { Estação } \\
\text { de Coleta }\end{array}$ & $\begin{array}{c}\text { Identificação } \\
\text { utilizada no texto }\end{array}$ & $\begin{array}{c}\text { Profundidade } \\
\text { de Amostragem }(\mathrm{m})\end{array}$ \\
\hline 35 & $35-10$ & 7,84 \\
& $35-20$ & 20,20 \\
36 & $36-5$ & 5,74 \\
& $36-10$ & 10,57 \\
38 & $36-\mathrm{F}$ & FUNDO $(14,50)$ \\
& $38-5$ & 4,39 \\
& $38-7$ & 7,76 \\
40 & $38-14$ & 14,48 \\
& $38-\mathrm{F}$ & FUNDO $(18,00)$ \\
59 & $40-12$ & 11,197 \\
74 & $40-\mathrm{F}$ & FUNDO $(16,50)$ \\
75 & $59-5$ & 4,12 \\
78 & $74-5$ & 4,08 \\
& $74-10$ & 14,11 \\
& $75-5$ & 4,32 \\
& $75-10$ & 10,58 \\
& $78-5$ & 4,25 \\
& $78-10$ & 10,11
\end{tabular}

\section{Análises}

- Matéria Orgânica

Análises de infravermelho foram utilizadas, principalmente para detectar a presença de matéria orgânica e, atuando como ferramenta acessória, identificar qual o tipo de matéria orgânica. Utilizouse para determinação dos espectros a técnica de disco $\mathrm{KBr}$ a uma concentração aproximada de $1 \%$. A amostra é pulverizada e homogeneizada simultaneamente; somente depois é comprimida à alta pressão em molde evacuado de modo a formar uma pastilha. $\bigcirc$ registro espectral foi feito na região de $4000 \mathrm{~cm}^{-1}$ a $400 \mathrm{~cm}^{-1}$ em espectrofotômetro Perkin-Elmer, modelo FTIR 1760x, acoplado a um registrador automático.

- Análise Termogravimétrica

Determinou-se a variação na perda de água das amostras por meio do aquecimento entre $0^{\circ} \mathrm{C}$ e $1000^{\circ} \mathrm{C}$ em um intervalo de $10^{\circ} \mathrm{C} / \mathrm{min}$ em aparelho da marca Du pont Instruments Analyzer 915 Thermogravimetric Analyzer (TGA), acoplado a um registrador automático.

- Parâmetros Químicos e Físicos

Determinou-se carbono, nitrogênio e hidrogênio elementar nas amostras de sedimento, através da técnica de microcromatografia, utilizando-se um analisador de CHN, Hewlett Packard, modelo 185, dotado de microbalança eletrônica Cahn, modelo G com capacidade de 100-0,001 mg e um registrador Honeywell, modelo 16. Empregou-se como catalisador $\mathrm{MnO}_{2}-\mathrm{WO}_{3}(2: 1)$. Todas as análises de carbono, hidrogênio e nitrogênio foram realizadas no laboratório Ingeominas (Bogotá, Colômbia). O fósforo total foi dosado por espectrofotometria de absorção na região do visível (formação do complexo azul, com leitura em $510 \mathrm{~nm}$ ). Os dados físicos (salinidade, temperatura e densidade) foram medidos em equipamento CTD (condutividade, temperatura e densidade) acoplado ao amostrador de águas do tipo Rossete.

- Mineralogia

Analisou-se a fração argilosa do material em lâmina orientada nas condições normal, sob atmosfera de glicol e de aquecimento. Utilizou-se, na análise, um difratômetro do tipo Philips PW 1050, com monocromador de grafite e tubo de ânodo de cobre, na faixa de varredura 0-35 2q, a 0,5 seg, sensibilidade de $1000 \mathrm{imp} / \mathrm{seg}$ e intensidade de $2 \times 10^{3}$.

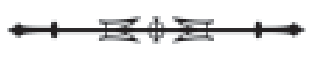




\section{RESULTADOS E DISCUSSÃO}

Os teores de material em suspensão (fração > $45 \mathrm{~mm}$ ) variaram de $48 \mathrm{mg} \cdot \mathrm{L}^{-1}$ a $2100 \mathrm{mg} \cdot \mathrm{L}^{-1}$ nas amostras analisadas (Tabela 2). As concentrações mais elevadas de material em suspensão (M.S) localizam-se em pontos de coleta mais próximos à costa e a menor concentração encontra-se a offshore. As correlações de Pearson entre material particulado e os dados físicos, tais como salinidade e densidade, levam a concluir que a distribuição do material em suspensão está inversamente associada ao aumento de salinidade e densidade, visto que no ponto em que há o máximo de material particulado ocorre o mínimo de salinidade (Figuras 2, 3 e 4). Não se observa uma boa correlação entre material em suspensão, a temperatura e o pH. Com relação à correlação entre material em suspensão e salinidade, esta já foi observada por vários pesquisadores como Gibbs (1970), estudando o rio Amazonas, e Chamley (1989), entre outros, para este tipo de ambiente.
As argilas identificadas por meio do difratograma de raios-X são caulinita (picos em aproximadamente 7,15 $\AA$, 3,57 $\AA$, em lâmina orientada normal), clorita (picos em aproximadamente 14,0 $\AA, 7 \AA$, 3,5 $\AA$ ), ilita (picos em aproximadamente $10 \AA, 5 \AA$ e 3,33 $\AA$ ) e, ainda, traços de esmectita (picos em aproximadamente $14,30 \AA$ em lâmina orientada normal e $17 \AA$ em lâmina orientada em atmosfera de glicol).

Analisaram-se amostras de material particulado em suspensão, algumas de sedimentos de fundo, nas quais se observou o amplo domínio de compostos inorgânicos como os argilominerais, silica, colóides de ferro e titânio sobre a matéria orgânica contida nas amostras.

O carbono ocorre em ecossistemas aquáticos costeiros como carbono orgânico vivo (integrante da biomassa) ou detrítico, carbonatos (geralmente bioclásticos) e na forma de carbono orgânico dissolvido. Esta última forma assume grande importância especialmente em ambientes marinhos.

Tabela 2. Apresentação dos dados físicos, químicos e físico-químicos do material em suspensão e sedimentos de fundo.

\begin{tabular}{|c|c|c|c|c|c|c|c|c|c|c|c|c|c|c|}
\hline Est. Amost. & M.S. & $S$ & $\mathrm{D}$ & $T$ & $\mathrm{pH}$ & C & $N$ & $\mathrm{H}$ & $\mathrm{H} / \mathrm{C}$ & $\mathrm{C} / \mathrm{N}$ & P & $C / P$ & $\mathrm{Fe}$ & M.O. \\
\hline $35-10$ & 250 & 34,76 & 22,77 & 26,26 & 8,15 & 1,25 & 0,13 & 0,96 & 0,77 & 9,64 & 0,53 & 2,36 & 8,19 & 2,15 \\
\hline $36-5$ & 2300 & 24,31 & 14,42 & 27,88 & 7,86 & 1,39 & 0,03 & 0,77 & 0,55 & 46,33 & 0,06 & 23,17 & 7,58 & 2,38 \\
\hline $36-10$ & 1450 & 25,38 & 15,22 & 27,87 & 7,97 & 1,11 & 0,03 & 0,83 & 0,75 & 37 & 0,13 & 8,54 & 9,06 & 1,91 \\
\hline 36-F & - & - & - & - & - & 1,56 & 0,03 & 0,77 & 0,49 & 52 & 0,14 & 11,14 & 9,53 & 2,68 \\
\hline $38-14$ & 450 & 33,81 & 21,79 & 27,1 & 8,09 & 1,38 & 0,06 & 1,01 & 0,73 & 23 & 0,07 & 19,71 & 6,91 & 2,37 \\
\hline 38-F & - & - & - & - & - & 1,51 & 0,03 & 1,33 & 0,88 & 50,3 & 0,09 & 16,78 & 6,87 & 2,60 \\
\hline $40-12$ & 200 & 35,6 & 23,4 & 26,27 & 8,22 & 1,68 & 0,06 & 1,52 & 0,9 & 23 & 0,17 & 9,88 & 6,47 & 2,37 \\
\hline $40-\mathrm{F}$ & - & - & - & - & - & 2,05 & 0,03 & 0,89 & 0,43 & 68,3 & 0,09 & 22,78 & 8,54 & 3,53 \\
\hline $74-5$ & 220 & 35,62 & 22,6 & 28,8 & 8,13 & n.d. & n.d. & n.d. & n.d. & n.d. & 0,23 & n.d. & 7,05 & n.d. \\
\hline $74-14$ & 80 & 35,91 & 22,81 & 28,8 & 8,17 & n.d. & n.d. & n.d. & n.d. & n.d. & 0,64 & n.d. & 3,72 & n.d. \\
\hline $75-5$ & 410 & 28,06 & 16,97 & 28,7 & 8,09 & 1,27 & 0,1 & 0,67 & 0,53 & 12,7 & 0,48 & 2,67 & 7,81 & 2,18 \\
\hline $75-10$ & 200 & 29,62 & 18,1 & 28,81 & 8,01 & n.d. & n.d. & n.d. & n.d. & n.d. & 0,78 & n.d. & 3,87 & n.d. \\
\hline $78-5$ & 200 & 36,57 & 23,34 & 28,55 & 7,86 & n.d. & n.d. & n.d. & n.d. & n.d. & 0,71 & n.d. & 7,52 & n.d. \\
\hline
\end{tabular}

Obs.: Est. Amost.-estação de amostragem; M. S.- material em suspensão (mg/L); S-salinidade (\%); D-densidade (g/L); T-temperatura $\left({ }^{\circ} \mathrm{C}\right)$; C-carbono (\%); N-nitrogênio (\%); H-hidrogênio (\%); P-fósforo (\%); Fe-ferro (\%); M. O.-matéria orgânica (\%); n.d.-não determinado.

Razões: $\mathrm{H} / \mathrm{C}$ obtida pelo quociente entre o percentual de $\mathrm{H}$ pelo do $\mathrm{C} ; \mathrm{C} / \mathrm{N}$ obtida pelo quociente entre o percentual de $\mathrm{C}$ pelo do $\mathrm{H}$; C/P obtida pelo quociente entre o percentual de $\mathrm{C}$ pelo do $\mathrm{P}$.

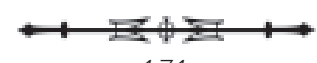


A decomposição da matéria orgânica provoca modificações nas características físico-químicas do ambiente, especialmente no sedimento, influenciando o ciclo biogeoquímico de vários elementos, e determinando a forma na qual eles estão presentes (BERNER, E.; BERNER, R., 1996).

Os teores encontrados para carbono elementar orgânico estendem-se de 1,11 a 2,05\%, enquanto que os de nitrogênio, de 0,03 a $0,13 \%$, teores esses que produzem índices de relação $\mathrm{C} / \mathrm{N}$ variando de 9,64 até o máximo de 68,3. Estes últimos caracterizam, provavelmente, um material rico em produtos de decomposição de celulose, de origem vegetal.

As concentrações mais elevadas de carbono estão nos sedimentos de fundo e os teores mais elevados no material em suspensão aparecem em profundidades mais superficiais, ocorrendo, ainda, ao longo da coluna d'água, teores relativamente elevados, que são, possivelmente, devidos às contribuições originárias de ressuspensão do carbono de fundo. É notória a ocorrência dessas associações em pontos próximos à costa do Amapá, deslocandose para noroeste.

A distribuição do carbono orgânico terrestre e marinho em sedimentos superficiais está relacionada aos vários processos que são controlados pela sedimentação sobre a plataforma continental do Amazonas. A acumulação lenta em áreas próximas à costa parece ser a incorporação de quase a totalidade do carbono orgânico total; entretanto, a mais rápida acumulação de sedimentos próxima à margem externa dos depósitos de lama moderna contém um aumento em porcentagem de carbono orgânico marinho; as regiões de fundo têm uma baixa taxa de acumulação e estão acumulando, predominantemente, carbono orgânico marinho (SHOWERS; ANGLE, 1986).

Showers e Angle (1986), estudando o estuário do Amazonas, sugerem que o carbono orgânico terrestre seja transportado para o noroeste ao longo da coluna de água inteira no limite do norte de sua área de estudo, havendo grandes diferenças isotópicas entre carbono orgânico particulado em amostras de superfície e água de fundo. Tais diferenças, provavelmente, são causadas por produtividade marinha em águas de superfície e ressuspensão de carbono orgânico.

Nas amostras de sedimentos em suspensão e fundo selecionadas para a análise neste trabalho, predominam os compostos inorgânicos (argilominerais, síica e colóides de ferro), ficando a matéria orgânica com um conteúdo sempre abaixo de 3,6\% (Tabela 2). Portanto, na interpretação dos registros de espectros de absorção na região do infravermelho, as bandas mais intensas estão relacionadas com os argilominerais dominantes no material, ou seja, a mistura ilita e caulinita.

As bandas relativas às ligações químicas nos argilominerais dominam nos espectros aqui registrados (Figura 5) pelas razões já expostas. A nítida e intensa banda de vibração do estiramento Si-O, que se estende desde 1200 a $1000 \mathrm{~cm}^{-1}$, com seus desdobramentos mais significativos às proximidades de 1180 e $1034 \mathrm{~cm}^{-1}$ (espectros I, II e III, Figura 5), é bem representativa de estruturas do tipo illita e caulinita, confirmando os resultados oriundos da difração de raios-X. Também é importante considerar as outras bandas associadas aos argilominerais: a nítida banda, com fracos dobramentos em torno de 950 a $915 \mathrm{~cm}^{-1}$, relativa à ligação $\mathrm{Al}-\mathrm{OH}$; as bandas às proximidades de 790 a 800,750 a 780,640 a $690 \mathrm{~cm}^{-1}$ ou no intervalo de 400 a $600 \mathrm{~cm}^{-1}$; as intensas bandas de absorção registradas no intervalo de 4000 a $3400 \mathrm{~cm}^{-1}$, com seus vários desdobramentos, relacionadas às ligações com hidroxila, $-\mathrm{OH}$, tão comuns em argilominerais (GADSDEN, 1975; MAREL; BEUTELSPACHER, 1976; OLPHEN; FRIPIAT, 1979). Importante, ainda, é a intensa e média banda registrada às proximidades de $1640 \mathrm{~cm}^{-1}$, correspondente à deformação angular da ligação $\mathrm{HOH}$, característica de água de constituição presente nos argilominerais (OLPHEN; FRIPIAT, 1979).

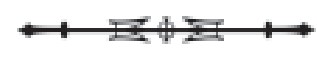




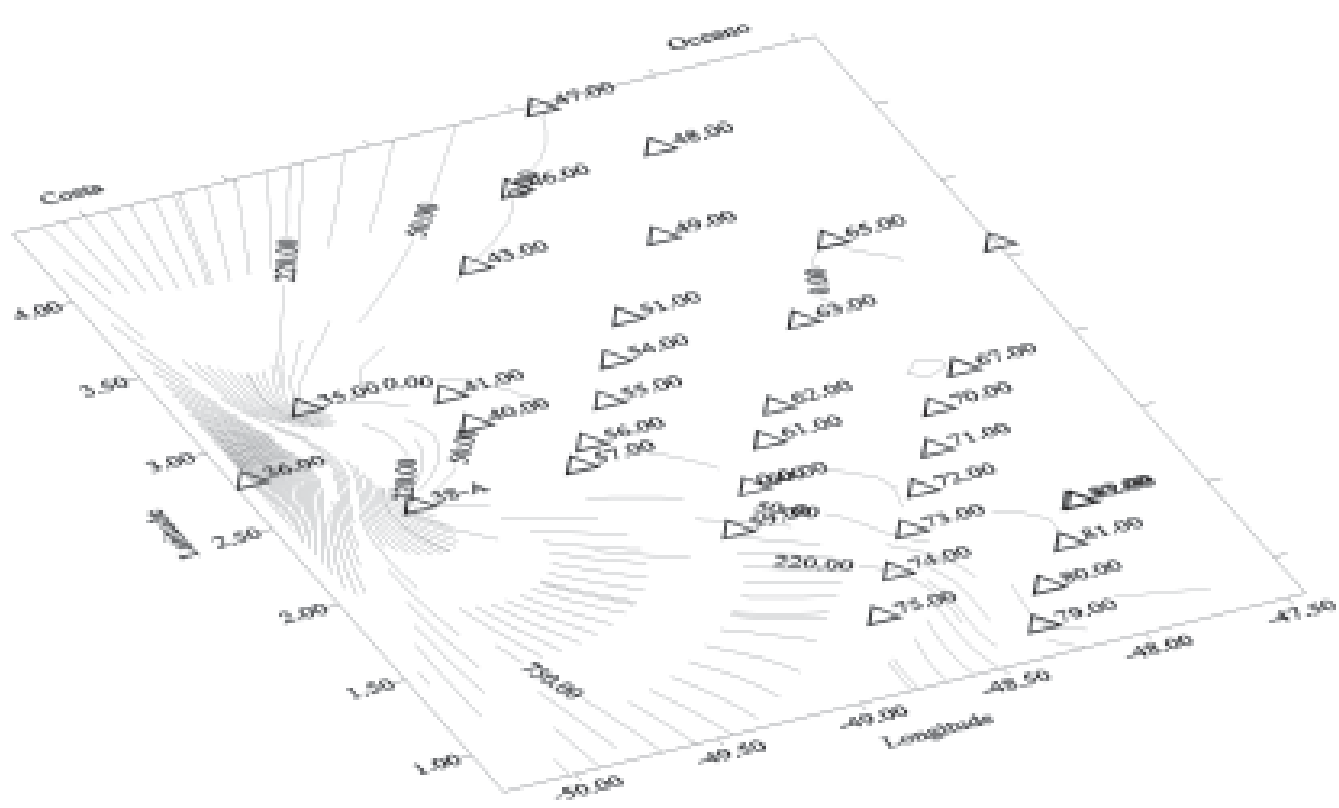

Distribuição horizontal de material em suspensão (profundidade entre 3 e 6 m).

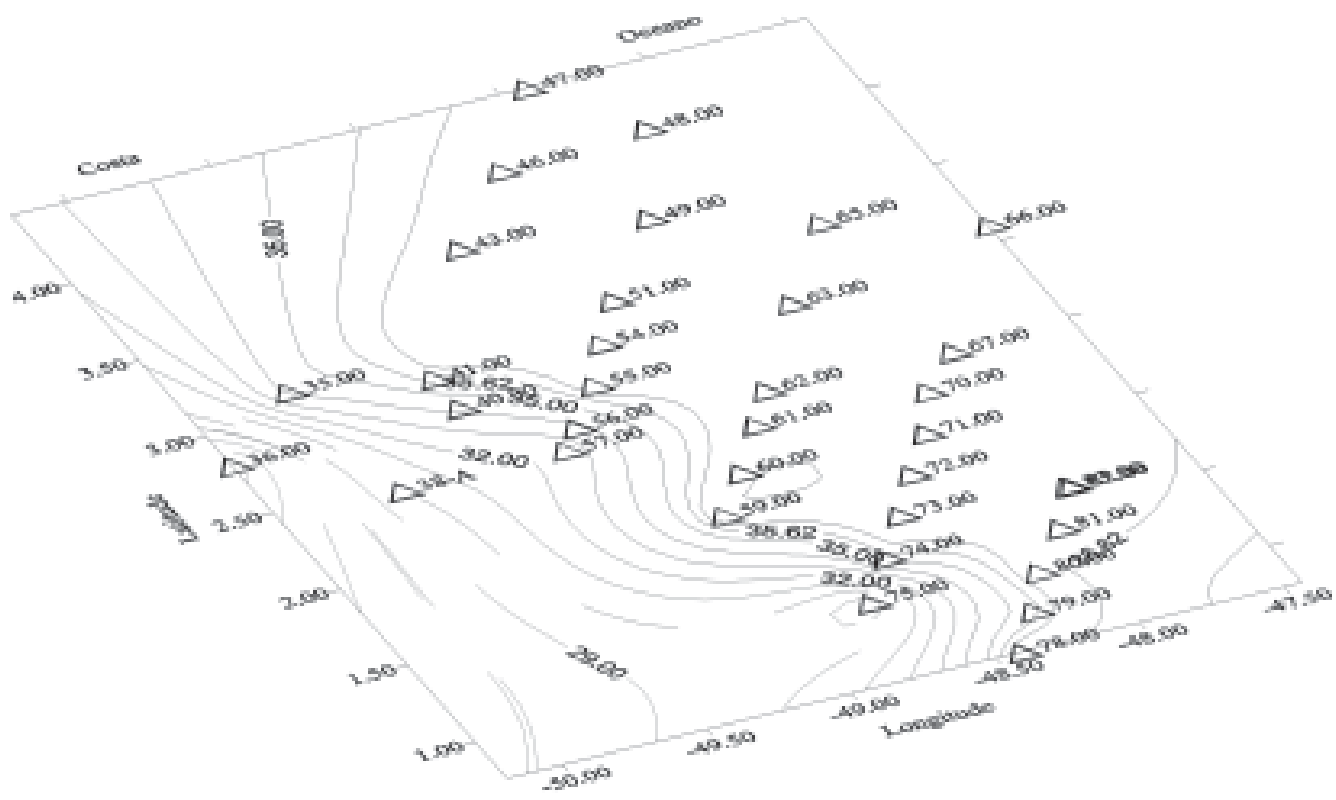

Distribuição horizontal de salinidade (profundidade entre 3 e 6 m).

Figura 2. Isolinhas exibindo a progressão do material em suspensão ao longo das estações de coleta, associadas ao gráfico da progressão da salinidade, ambas com profundidade entre 3 e 6 m.

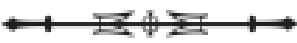




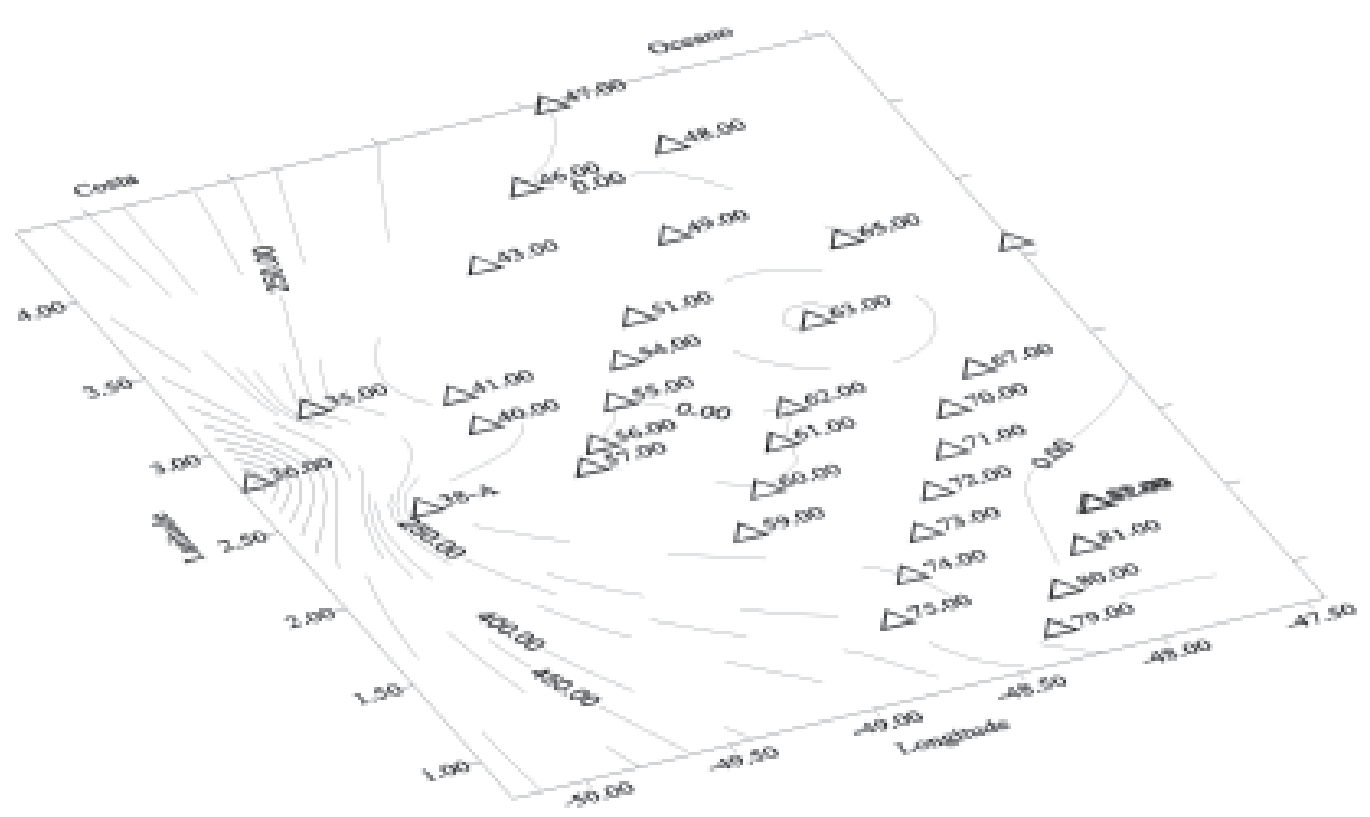

Distribuição horizontal de material em suspensão (profundidade entre 6 e 12 m).

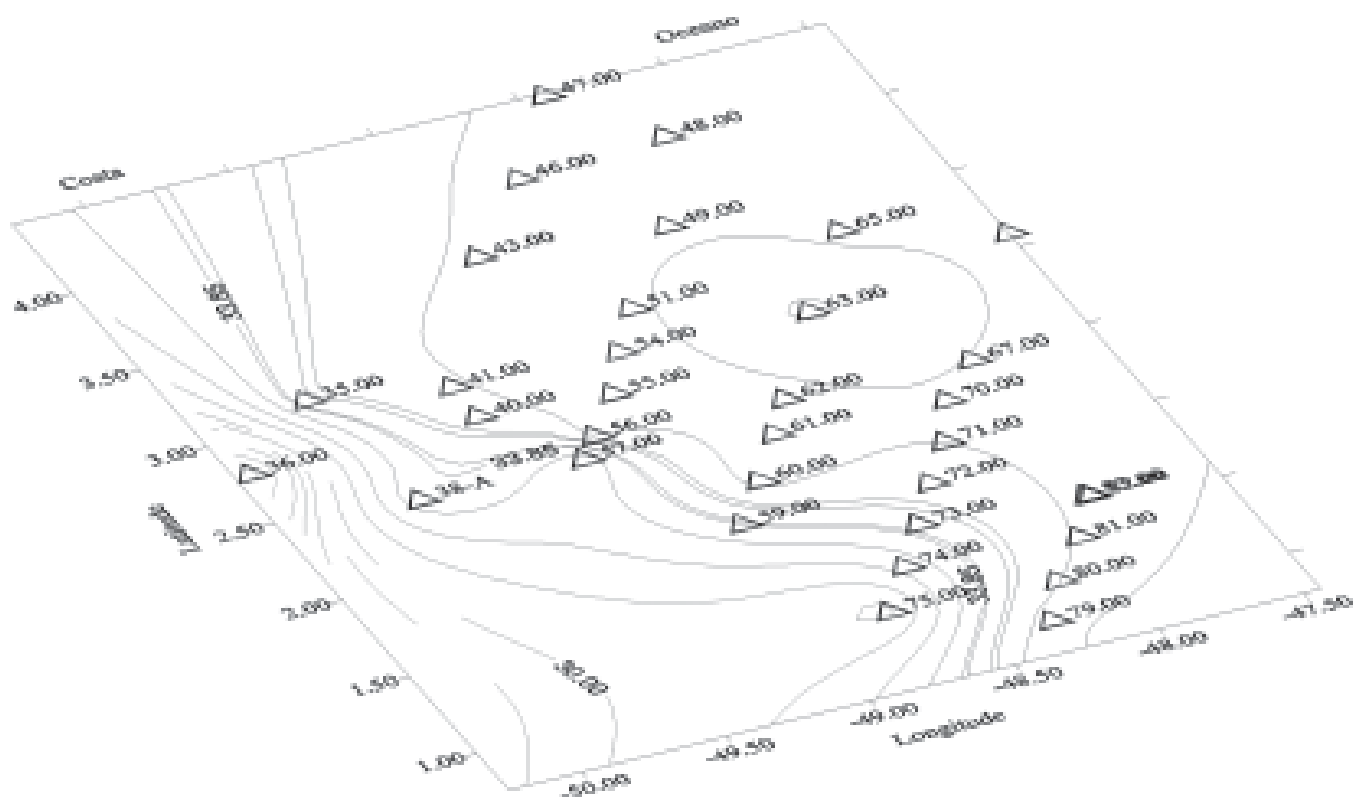

Distribuição horizontal de salinidade (profundidade entre 6 e $12 \mathrm{~m}$ ).

Figura 3. Isolinhas exibindo a progressão do material em suspensão ao longo das estações de coleta, associadas ao gráfico da progressão da salinidade, ambas com profundidade entre 6 e $12 \mathrm{~m}$.

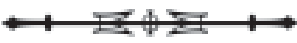




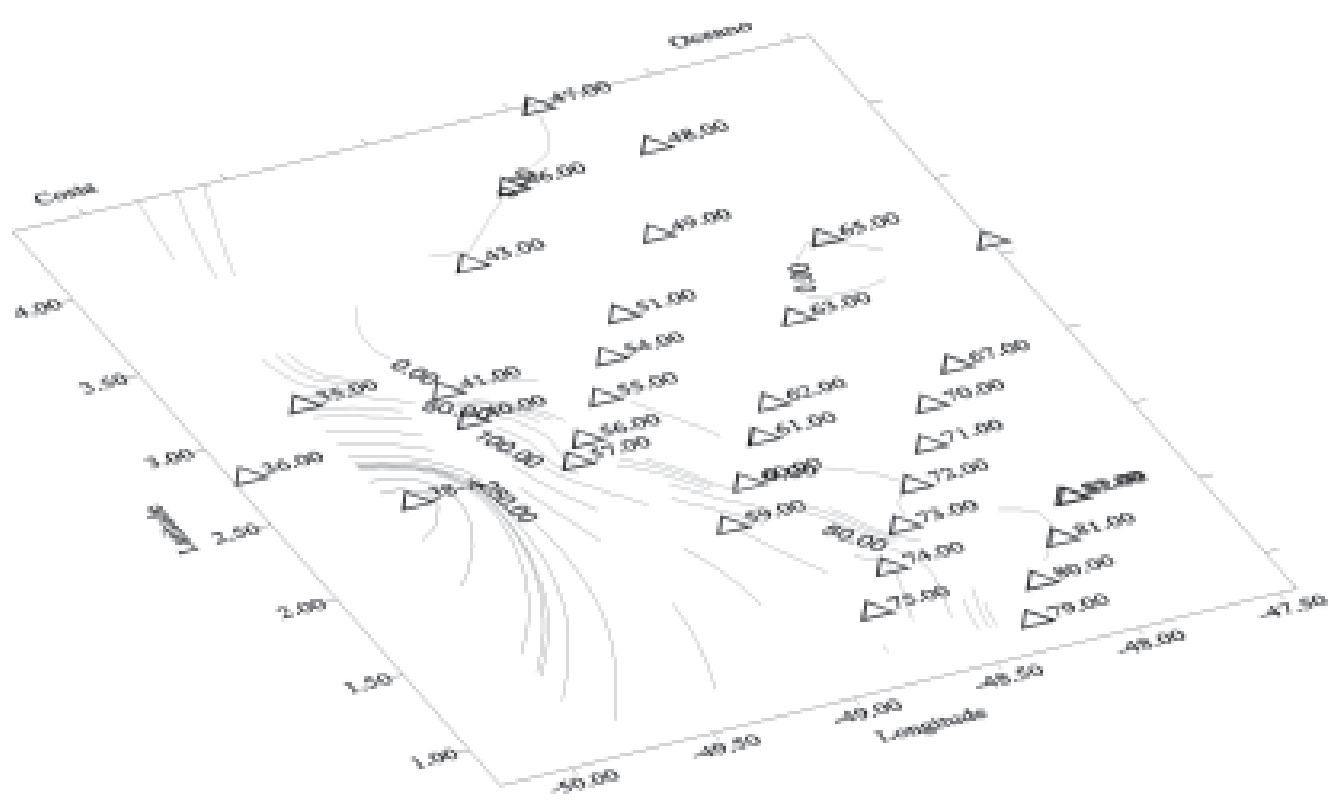

Distribuição horizontal de material em suspensão (profundidade entre 12 e 18 m).

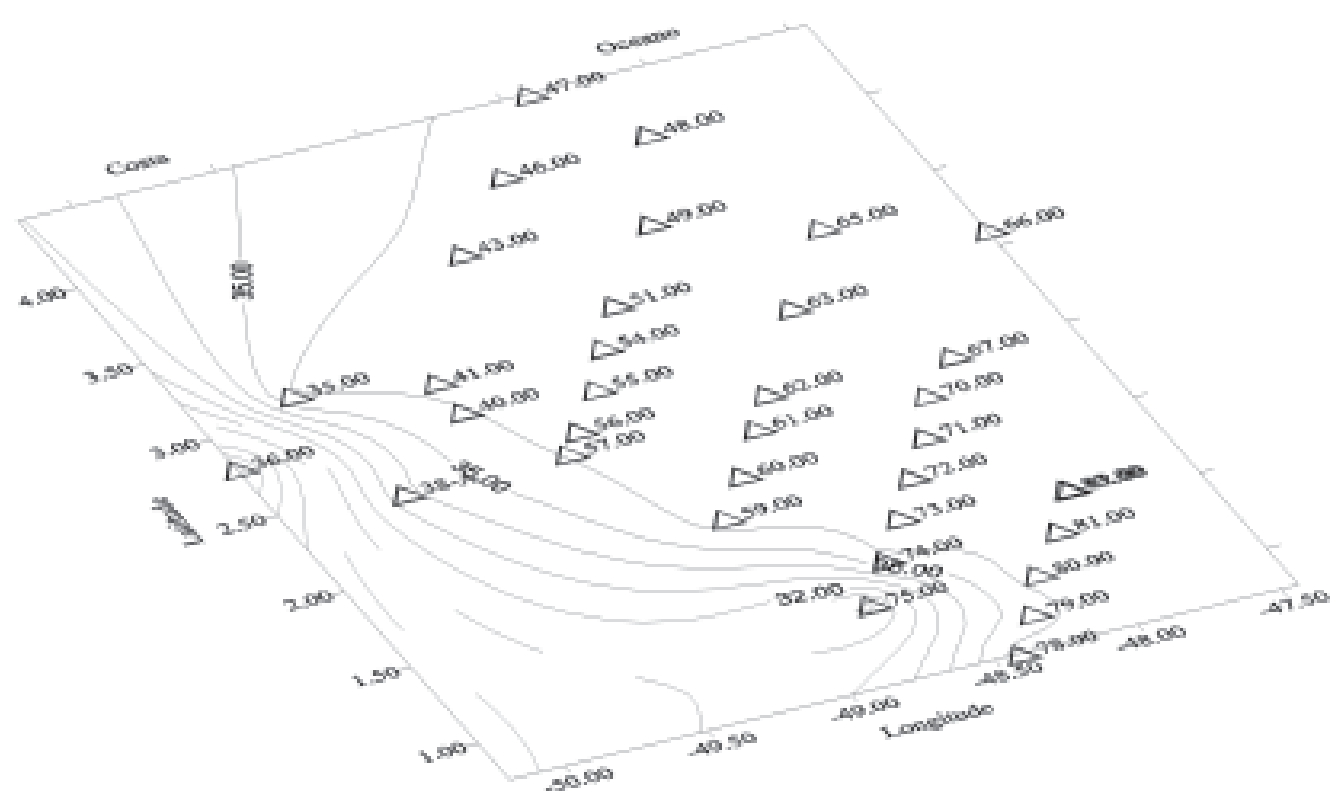

Distribuição horizontal de salinidade (profundidade entre 12 e 18 m).

Figura 4. Isolinhas exibindo a progressão do material em suspensão ao longo das estações de coleta, associadas ao gráfico da progressão da salinidade, ambas com profundidade entre 12 e $18 \mathrm{~m}$.

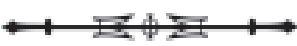


A composição química dos detritos orgânicos de plantas e animais (incluindo microorganismos de solo e da floresta) é bastante complexa e variada. As substâncias predominantes nas frações orgânicas de solos são a celulose, lignina, proteínas e misturas de compostos de elevado peso molecular, de coloração castanho-escura e composição química variada, dependendo do tipo de solo e das condições de clima. Esses compostos orgânicos, de coloração castanho-escura, consistem, predominantemente, de frações denominadas ácidos húmicos e fúlvicos (DEGENS; KEMPE; RICHEY, 1991).

Os espectros de absorção na região do infravermelho de ácidos húmicos e fúlvicos, de diferentes origens, são semelhantes, porém, não são idênticos. As diferenças (sutis) são resultantes de breves alterações em suas composições. Talvez a característica mais interessante do espectro de ácidos húmicos seja o aparecimento de intensas e largas bandas de absorção relacionadas com as vibrações de estiramento da ligação $C=O$ de vários grupos funcionais orgânicos (ácidos carboxílicos e seus derivados, aldeídos, cetonas), no intervalo de 1709 a $1715 \mathrm{~cm}^{-1}$ e de vibrações de compostos aromáticos às proximidades de $1600 \mathrm{a} 1613 \mathrm{~cm}^{-1}$. As bandas registradas às proximidades de $1698 \mathrm{a}$ $1701 \mathrm{~cm}^{-1}$ e em torno de $1400 \mathrm{~cm}^{-1}$ indicam a presença de grupos carboxila e carbonila.

Os aspectos mais interessantes dos espectros registrados para três amostras, aqui selecionadas (espectros I, II e III, Figura 5), dizem respeito ao aparecimento das nítidas, porém fracas, bandas de absorção no intervalo de 2959 a $2855 \mathrm{~cm}^{-1}$, atribuídas aos grupos metileno $-\mathrm{CH}_{2}$ - de hidrocarbonetos; e à presença de fraca, porém nítida, banda em torno de $1385 \mathrm{~cm}^{-1}$ referente aos grupos carboxila e carbonila.

A interpretação mais imediata desses resultados leva à conclusão de tratar-se de material húmico presente na matéria orgânica oriunda de lixiviações e drenagem de solos amazônicos típicos, tais como podzólicos e latossólicos (Figura 5).
Com efeito, a julgar pela predominância desses tipos de solos em áreas da floresta amazônica (equatorial, quente e úmida) ao longo das margens do curso do Amazonas, pela notável presença de material húmico nessas águas fluviais (LEENHEER, 1980) e pelo transporte e despejos desse material nas águas costeiras do oceano Atlântico, à foz do grande rio, é de se esperar que haja, ainda, influência de material húmico na matéria orgânica transportada pelos sedimentos em suspensão.

Segundo as observações de Ertel et al. (1986), para o sistema rio Amazonas, as substâncias húmicas combinadas representam $60 \%$ do carbono orgânico dissolvido fluvial, com razão ácido fúlvico para ácido húmico (af:ah) dos tributários com média de $4,7 \pm 1$; todos os ácidos húmicos e fúlvicos dissolvidos têm claramente identificados lignina na superfície (8 e 3\% de carbono), sugerindo uma fonte predominantemente alóctone.

Os dados de Fox, Sager e Wofsy (1986) indicam uma perda de fosfato significativa de águas estuarinas com salinidades entre 0 e 4 ppt, possivelmente associado com ferro e remoção de humato, e mais que $50 \%$ do fluxo determinado poderia ser contribuição do fosfato lançado de sedimentos em suspensão, dentro da parte turva do estuário.

As salinidades aqui consideradas estão em um intervalo entre 24,31 。 e 35,62\%, observando-se queda no teor de fosfato (Tabela 2) associada à diminuição de salinidade; confirmada pelas correlações de Pearson entre fósforo e salinidade positiva de $0,58332 * * *$. Porém, no que se refere ao ferro, não se distingue as mesmas associações entre fósforo e salinidade, pois a correlação entre ferro e salinidade é negativa de $-0,52022 * * *$. Acredita-se que, embora em salinidades muito baixas, os mecanismos de remoção de fósforo e ferro sejam análogos em salinidades de estuários; crê-se, também, que nas salinidades trabalhadas esteja ocorrendo remoção de fósforo e de humato. Tais associações também foram observadas por Fox et al. (1986), que expõem a existência de um

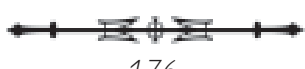




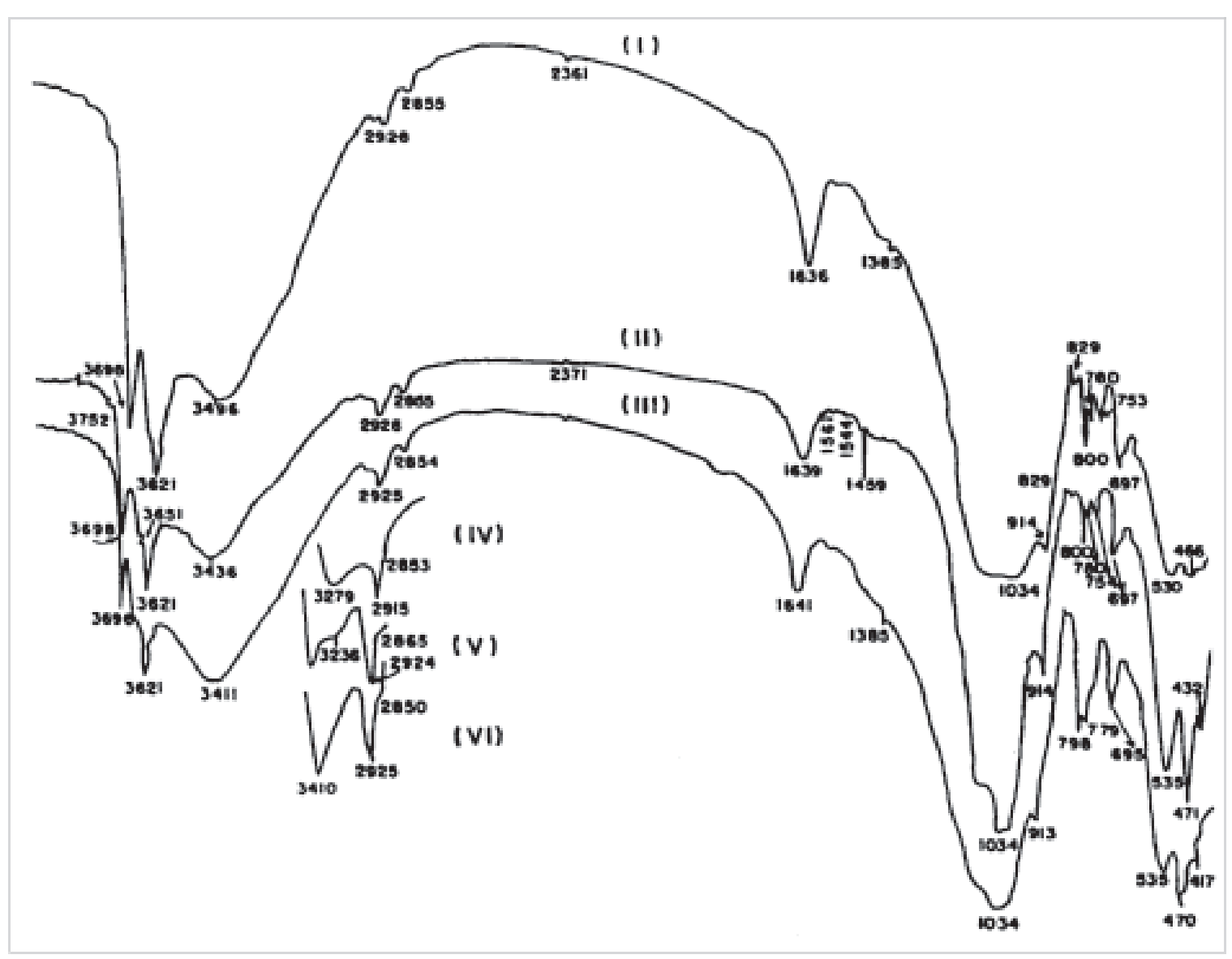

Figura 5. Espectros de absorção na região do infravermelho. Prensagem em KBr. Sedimentos em suspensão e de fundo (águas costeiras sob a influência do rio Amazonas). Espectros de amostras selecionadas (I, II, II); detalhes (extratos) ampliados de espectros coletados na literatura por Marel e Beutelspacher, 1976 (IV, V e VI).

decréscimo nas concentrações de fósforo inorgânico entre 0 e 4 ppt de salinidade, sugerindo uma remoção de fosfato em baixas salinidades. No presente estudo acredita-se que, possivelmente, o fósforo esteja sofrendo retirada biogeoquímica em salinidades tendendo a $24,31 \%$, enquanto que, em salinidades próximas a $35,62 \%$ o aumento observado no teor de fósforo seja devido principalmente às contribuições oceânicas de fósforo biogênico.

Alguns autores sugerem que distribuições de fosfato em muitos estuários podem refletir equilíbrio com minerais sedimentares (LISS, 1976) por mecanismos químicos semelhantes aos observados em áreas continentais (MATTINGLY, 1975).

Quanto à distribuição em profundidade de fosfato (variação de 0,06 a 0,78\%), observa-se uma distribuição variada nos sedimentos em suspensão (Tabela 2), o que, segundo Fox, Sager e Wofsy (1986), trata-se de aportes devidos à ressuspensão de sedimentos de fundo em várias localizações no estuário. Nas amostras analisadas, o fósforo não apresentou uma boa correlação com a salinidade, confirmando, de certa forma, os dados reportados por Liss (1976), que afirma que a concentração de fósforo apresenta um comportamento conservativo permanecendo

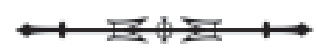


praticamente invariável por toda extensão de salinidade. O comportamento conservativo é possível devido aos processos inorgânicos de remoção e liberação de fosfato. Em águas aeradas, o fosfato precipita, adsorvido a oxi-hidróxidos férricos, enquanto que em ambientes anóxicos este ferro é reduzido, tornando-se mais solúvel e liberando o fosfato adsorvido (LSS, 1976). Admite-se, ainda, que num mesmo estuário podem ocorrer esses dois processos simultaneamente em diferentes áreas, ou em um mesmo trecho podem alternar-se entre ambas as condições (BERNER, E.; BERNER, R., 1996); esses fatores também poderiam explicar a razoável variação vertical e horizontal de fósforo.

\section{CONCLUSÃO}

Conforme o previsto, observou-se que as concentrações mais elevadas de material em suspensão (máxima em 2300 mg/L) encontram-se em pontos de coleta próximos à costa (como as estações 36,38 e 78) e tendem a zero a offshore; coerentes com tais resultados, a salinidade mostrou-se inversamente proporcional ao material particulado em suspensão, quando se considera a distribuição horizontal; a distribuição vertical do material em suspensão parece muito mais associada a fatores como a ressuspensão e mistura vertical. A variação do teor da matéria orgânica associada a esse material em suspensão é relativamente restrita, com teores mínimos em 1,91\% e valores máximos em 3,53\%.

A identificação da natureza química da matéria orgânica pela espectroscopia no infravermelho levou à ocorrência de material húmico provavelmente dominante nessa fração orgânica; que está associado, muito provavelmente, à drenagem de solos amazônicos característicos, como os podzóis e os latossolos, material esse transportado pelo rio Amazonas até às águas costeiras.

Na caracterização química do material húmico, a interpretação dos espectros de absorção levou à identificação de grupos metileno (que estão diretamente relacionados com hidrocarbonetos alifáticos), de grupos $\mathrm{C}=\mathrm{O}$ (de carboxilato e de cetonas) e de bandas devidas a argilominerais associados.

teor de matéria orgânica mostrou-se sempre abaixo de 3,6\%, exibindo valores de razão $\mathrm{C} / \mathrm{N}$ variando de 9,64 (material em suspensão) a 68,3 (em sedimentos de fundo), o que indica que a variação está associada com a maior ou menor influência de compostos orgânicos nitrogenados e de maior ou menor período de maturidade desse material orgânico. Nas amostras que apresentam razão $\mathrm{C} / \mathrm{N}$ mais elevadas, é provável uma origem em que dominem produtos da decomposição de celulose ou que estejam associadas a um período de maturação mais recente.

$\bigcirc$ teor de fosfato presente no sedimento, variando de $0,06 \%$ a 0,78\% (expressos em $\mathrm{mg} \cdot \mathrm{L}^{-1}$ de P), sendo este último 13 vezes superior àquele, sugere influências do ambiente marinho (talvez envolvendo contribuições de $P$ biogênico), através da ressuspensão de sedimentos, o que é comum em ambientes estuarinos

\section{REFERÊNCIAS}

BERNER, E. K.; BERNER, R .A. 1996. Global Environment: water, air and geochemical cycles. [S.l.s.n.n.]. Prentice Hall.

CHAMLEY, H. 1989. Clay sedimentology. [S.l.:s.n.]. 623 p. Springer - Verlag.

DEGENS, E. T.; KEMPE, S.; RICHEY, J. E. 1991. Biogeochemistry of Major World Rivers. Wiley: Brisbane. (Scope, 42).

ERTEL, J. R. et al. 1986. Dissolved humic substances of the Amazon river system. Limnol. Oceanogr., v. 31, n. 4, p. 739-754.

FOX, L. E.; SAGER, S. L.; WOFSY, S. C. 1986. The chemical control of soluble phospurus in the Amazon estuary. Goechimica et Cosmochimica Acta, v. 50, p. 783-794.

GADSDEN, J. A. 1975. Infrared spectra of minerals and related inorganic compounds. Chichester: Betterworths.

GIBBS, R. J. 1970. Circulation in the Amazon River Estuary and the adjacent Atlantic Ocean. Journal of Marine Research, v. 28, p. 113-123.

LEENHEER, J. A. 1980. Origin and nature of humic substances in the waters of the Amazon river basin. Acta Amazonica, v. 10, n. 3, p. 513-526.

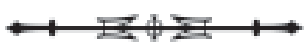


Bol. Mus. Para. Emilio Goeldi. Ciências Naturais, Belém, v. 1, n. 1, p. 167-179, jan-abr. 2006

LSS, P. S. 1976. Conservative and non-conservative behavior of dissolved constituents during estuarine mixing. In: BURTON, J. B.; LISS, P. S. Estuarine chemistry. London: Academic Press. 299 p. v. 4.

MAREL, H. Van Der; BEUTELSPACHER, H. 1976. Atlas of infrared spectroscopy of clay minerals and their admixtures. Elsevier: Amsterdam.

MATTINGLY, G. E. G. 1975. Labile phosphate in soils. Soil Sci., v. 119, p. 360-375
OLPHEN, H. Van; FRIPIAT, J. J. 1979. Data handbook for clay minerals and other non-metallic minerals. Oxford: Pergamon Press.

SHOWERS, W. J.; ANGLE, D. G. 1986. Stable isotopic characterization of organic carbon accumulation on the Amazon continental shelf. Continental Shelf Research, v. 6, p. 227-244. 